\title{
Review of Geoinformatics-Based Forest Fire Management Tools for Integrated Fire Analysis
}

\author{
Stavros Sakellariou ${ }^{1,2 *}$, Athanassios Sfougaris ${ }^{1}$, Olga Christopoulou ${ }^{2}$ \\ ${ }^{1}$ Department of Agriculture Crop Production and Rural Environment, University of Thessaly, 38446 Volos, Greece \\ ${ }^{2}$ Department of Planning and Regional Development, University of Thessaly, 38334, Volos, Greece
}

Received: 8 December 2020

Accepted: 8 April 2021

\begin{abstract}
Wildfires of high severity can have profound implications on natural and human environment affecting the quality of life; the health of living beings; and the prosperity of any society. Consequently, specific strategies, tactics and techniques should always be adopted for the alleviation of this critical phenomenon. Hence, the aim of the paper is the review of the most common geoinformatics-based techniques contributing to an integrated fire analysis through four pillars. The first one is related with the fire exposure on the ground, primarily analyzing the fire susceptibility in terms of fire risk and burn probability maps; The second one examines the fire effects on the most critical ecological and anthropogenic resources and infrastructures. The third pillar combines two effective geospatial tools supporting the wildfire prevention and suppression, such as the visibility analysis for early detection of fire hotspots and the network analysis for strategic and operational planning of fire events. Last, the Earth-Observation module, through the spatiotemporal monitoring and prediction of land use changes, permits the planners to evaluate the underlying pressures (fires, urbanization) against forests developing the appropriate planning guidelines. In the meantime, new perspectives emerge. Novel machine learning algorithms and remote sensing data techniques are expected to improve the fire risk/probability credibility enhancing the more precise identification of fire effects to any resource. The integration of specific geographic criteria (e.g. topography, accessibility) and programming techniques (e.g. maximizing the visible area) to visibility analysis would empower the immediate fire detection. New technologies such as the adoption of drones would be a cost-effective tool for quick retrieval of vital geo-data. Network analysis could propose financially and environmentally efficient location schemes of fire agencies and resources.
\end{abstract}

Keywords: wildfires, fire prevention, fire risk/probability, fire effects, visibility analysis, network analysis, land use change, geographical information systems (GIS), remote sensing

*e-mail: stasakel@gmail.com 


\section{Introduction}

Wildfires of high severity can have profound implications on natural and human environment [17]. Two of the most catastrophic wildfires recorded lately have immensely affected the natural and the anthropogenic/built environment. The first one happened in Amazon strongly affecting the endemic flora and fauna, whereas the second one occurred in Greece killing dozens of people and destroying the residential web [8]. Climatic and economic factors tend to be the main drivers of such events [9-10].

Pechony and Shindell [11] mention that the most important driver of forest fires before industrial period used to be the amount of precipitation, whereas the most contributing factor seems to be the temperature in a future climate. The last conclusion comes to be confirmed by the climate change effect and the predicted global warming. Hence, the impacts of global warming may be prominent, since as the temperature increases (or projected to be increased) so as the wildfire activity in terms of longer fire season and more catastrophic fire events (increased fire severity, duration and frequency) [5]; [12-13]. Similar climate trends are expected for the Mediterranean countries including more extensive parts of the entire EU [14]. Even though a very small fraction of wildfires (less than 5\%) is accountable for the greatest burned area, those events are essential uncontrollable despite every possible effort (in terms of financial or human force/fire machinery perspective) [12]. One more critical aspect of this phenomenon is related with air pollution and the corresponding effects on human and animal health. Forest fires emit a great amount of carbon each year which is estimated to $40 \%$ of total fossil fuel carbon emissions [12] and approximately $3 \%$ of the total tropospheric ozone [15].

In a lower geographic scale, in the Mediterranean basin, there are some ecosystems that are successfully adjusted to forest fires and can be characterized more resilient (shrubs, oak forests), while others (pine forests) are quite vulnerable. In this context, high rates of erosion have been recorded, especially when fire events of high severity take place [16].

Finally, the large economic cost derived from wildfires should not be ignored. Indicatively, the last enormous wildfire in California killed 88 people and affected 18,500 artificial entities. Hence, the total financial cost yielded to 24 billion \$ including the firefighting mission costs and the impacts to buildings and infrastructure [17], without considering the hidden economic impact to human health which is translated to $9.5 \$$ as the cost of illness per person for each day during the forest fire event [18].

For all the above reasons which affect all the living beings from local to global environment, specific strategies, tactics and techniques should always be adopted for the alleviation of this critical phenomenon. Hence, the aim of the paper is the review of the most common geoinformatics-based techniques contributing to an integrated fire analysis. The scientific literature gives great importance on four distinct fields. The first one is related with the fire exposure on the ground, primarily analyzing the fire susceptibility in terms of fire risk and burn probability (BP) maps. The second one examines the fire effects on the most critical ecological and anthropogenic resources and infrastructures. The third field combines two effective tools supporting the prevention and suppression of forest fires, such as the visibility analysis for early detection of fire ignitions, and the network analysis for strategic and operational planning of fire events. Finally, the Earth-Observation module, which accounts for the spatiotemporal monitoring and prediction of land use changes, provides the planners with the appropriate tools to restrain the dominant forces (e.g. fires, urbanization) acting against forest ecosystems. The integration of all the above modules into a fire analysis framework may provide the appropriate strategy, tactics and measures for the prevention of disastrous fire events and the protection of ecological and cultural wealth.

\section{Risk Assessment and Fire Management Framework}

The development of an integrated theoretical framework that would feed the decision makers with necessary information may be composed by four discrete but quite interrelated pillars.

The first one constitutes the exposure analysis, as referred by several authors [19-20], which describes and analyzes the interaction of fires within any given territory. This process may include the fire risk identification based on surface features and fire modeling which is further divided to fire propagation and BP estimation. The output of this module may feed the next one, called effects analysis. The primary characteristics of effects analysis incorporate the collection of data and mapping concerning the resources at risk as well as the estimation of resource response to fire effects [19-21]. After the completion of these two modules, we will be able to recognize the most vulnerable regions and establish the respective protection priorities. The outputs of these modules in turn would feed the design and recommendation of the most appropriate prevention and suppression measures (fire management). Among them, two of the most cost-effective tools consist of visibility analysis which tries to achieve an efficient spatial scheme of observatories in order to detect any fire event timely. Another efficient measure constitutes the network analysis which can be exploited for strategic and operational purposes. The latter module could calculate the best routes between any fire vehicle and hotspot and could be used for the development of an effective location scheme for fire agency vehicles. Finally, the Earth Observation module has a more indirect effect. Monitoring the spatiotemporal evolution of land use changes, we may recognize the primary drivers that led to this effect, providing the opportunity 


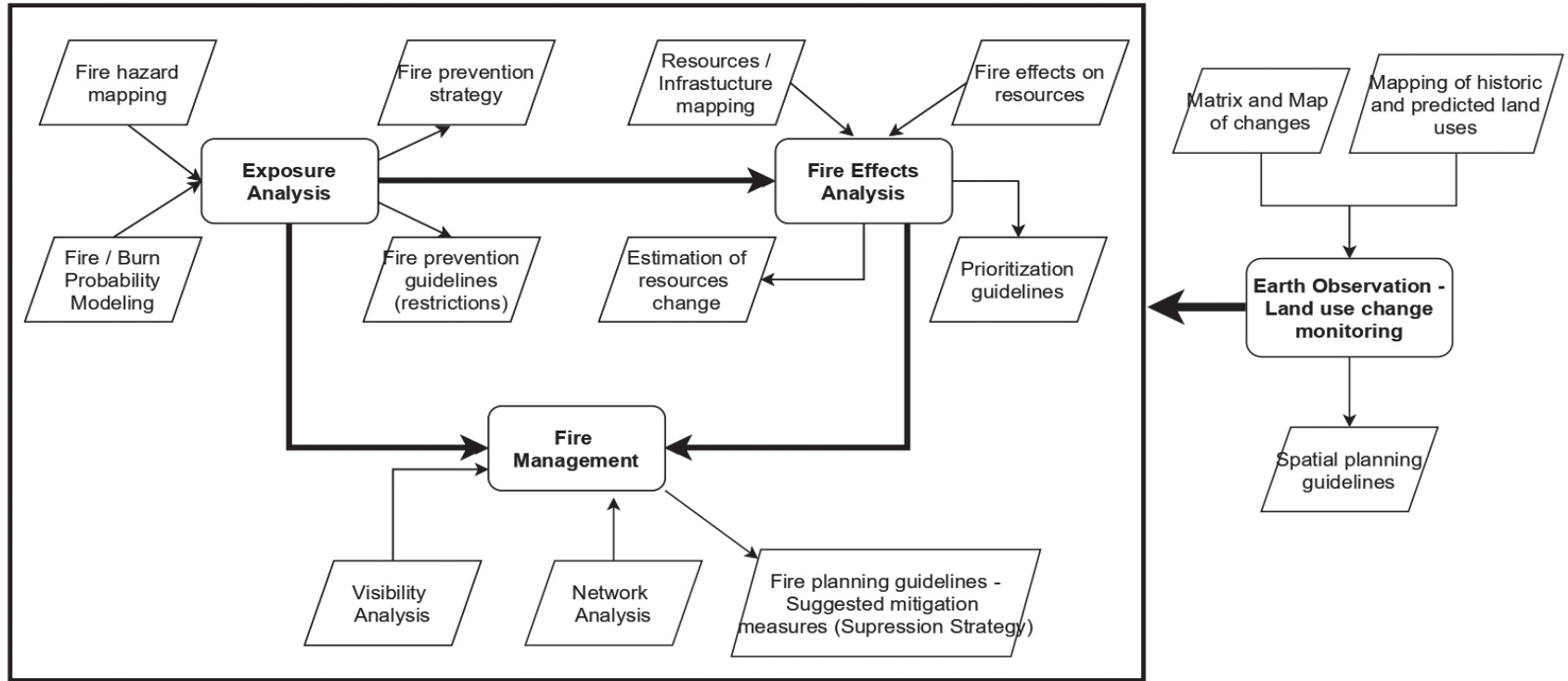

Fig. 1. Indicative modules and submodules for an integrated fire analysis.

to establish a planning framework to mitigate or reverse any economic pressure (urbanization; tourism etc.) which evolves in the expense of natural environment.

Fig. 1 illustrates the dimensions of a comprehensive fire analysis and the derived measures that comprise parts of those modules, whereas the Table 1 summarizes the primary fire modules and the analysis components accompanied by recent key sources.

\section{Results}

Exposure Analysis through Forest Fire Risk and Burn Probability

The estimation of forest fire risk and burn/fire probability constitute two significant pillars of fire prevention. The first process is usually related with the integration of many critical inputs through geographical information systems, experts' systems and statistical evaluation of impact for each contributing factor. The burn/fire modeling is based on the appropriate handling of these inputs employing probabilistic and deterministic sub-modules.
According to Parisien [22], BP maps may provide the essential information to locate the most susceptible regions suggesting the most appropriate preventative measures (adjusted to local characteristics). In the same context, spatial planning directions should be adopted beforehand, promoting the sustainable development of any region and securing the human integrity and protection of ecological and cultural assets. Consequently, certain factors should always be taken into consideration (fire history; geomorphology; climatic conditions), since these factors form the spatial pattern of BP and the estimated severity. As such, fire managers might be able to recognize specific regions where potential fire events may surpass the current initial attack forces, or regions rich of natural elements which might play a decisive role in fire propagation (natural barriers, such as water or rocky surfaces etc.).

Eugenio et al. [23] developed a forest fire risk map combining the Geographical Information Systems (GIS) and the Analytical Hierarchy Process (AHP). The primary inputs were based on several natural and artificial factors. Specifically, they created the meteorological maps through a series of spatial interpolation techniques (Exponential/Spherical Kriging

Table 1. Summary of fire analysis modules and primary sources.

\begin{tabular}{|c|c|c|}
\hline Fire module & Analysis & Key Sources \\
\hline Exposure Analysis & Fire risk & {$[23] ;[24] ;[25] ;[26] ;[27] ;[28] ;[29] ;[71] ;[72] ;[73] ;[89] ;[90] ;[91] ;$} \\
\hline Exposure Analysis & Simulation modeling & {$[21] ;[22] ;[30] ;[31] ;[32] ;[33] ;[34] ;[37] ;[69] ;[70] ;[92] ;[93] ;[94]$} \\
\hline Effects Analysis & Fire effects & {$[19] ;[21] ;[35] ;[36] ;[37] ;[38] ;[39] ;[42]$} \\
\hline Fire Management & Visibility analysis & {$[24] ;[43] ;[44] ;[45] ;[46] ;[47] ;[48] ;[49] ;[81] ;[95] ;[96]$} \\
\hline $\begin{array}{c}\text { Fire Management / Emergency } \\
\text { Response }\end{array}$ & Network analysis & {$[51] ;[52] ;[53] ;[54] ;[55] ;[56] ;[57] ;[58] ;[59] ;[60] ;[61] ;[62] ;$} \\
\hline Earth Observation & Land uses monitoring & {$[63] ;[64] ;[65] ;[66] ;[67] ;[68] ;[88] ;[97]$} \\
\hline
\end{tabular}


Interpolation). These climatic indices described the precipitation, evapotranspiration, water deficit and average temperature. Next, geomorphological maps have been included in fire risk analysis through the development of thematic maps describing the slope, elevation, aspect, land use and proximity to road network. The AHP has been used for the weighting process of each factor and the final fire risk map was overlapped with historic fire data for validation purposes. Sivrikaya et al. [24] created a fire risk map considering the factors that are conducive to forest fire ignition and propagation. These dimensions were related to forest fuel types, crown features as well as the development stage of forests. They calculated the topographic indices (slope and aspect) and the impact of human factor (especially in fire ignition) through the delimitation of proximity zones to roads and towns settlements as well as to agricultural fields. Finally, they combined the integrated fire risk map with the visibility analysis, so that they can efficiently cover the most vulnerable regions through the proposal of best location scheme of watchtowers. Sakellariou et al. [25] determined the spatiotemporal evolution of forest fire risk in a small island (Fig. 2a), based on the impact of topography, human intervention (e.g. land use change), vegetation and moisture status indices (Normalized Difference Vegetation Index - NDVI; Normalized Difference Moisture Index - NDMI). In this context, they proceeded to a comparative analysis of AHP and Fuzzy-AHP weighting schemes to select the most representative one. Finally, they performed a geostatistical analysis of fire risk to estimate the potential transmissibility of fire. Amalina et al. [26] proceeded to the fire risk estimation exploring the impact of similar factors and highlighted the higher relative significance of natural factors compared to anthropogenic ones (based on real fire history). In another context, Gabban et al. [27] adopted a differentiated approach for the estimation of fire risk. Collecting periodic satellite data of low spatial (high temporal) resolution, they created an index that associates the NDVI with its minimum and maximum values per day in the long run. This index was totally in line with the real fire history data.

On the other hand, Kant Sharma et al. [28] developed two fire risk maps based on differentiated techniques, namely, the Crisp and Fuzzy AHP of knowledge-based factors (fuels types and density; topography; proximity to anthropogenic structures) in order to alleviate the uncertainty inherited in fire modelling. In the same context, Vadrevu et al. [29] combined the AHP and Fuzzy logic capabilities in order to create the integrated fire risk map introducing additional (socioeconomic) factors that may affect the susceptibility of any region to fire risk, such as the density of population, the land uses competition in favor of agriculture, the education level etc.

Carmel et al. [30] developed a fire susceptibility map based on simulation modeling. They used the Farsite fire growth simulation model incorporating the most contributing factors (topography, fuels, climatic data, fire ignitions data etc.). The cumulative result of the a)

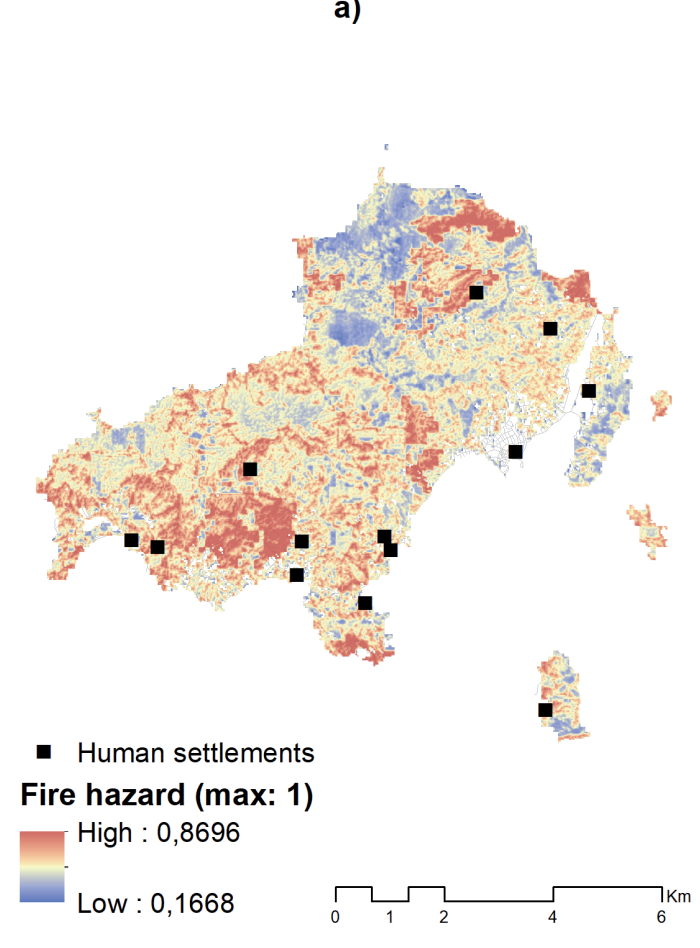

b)

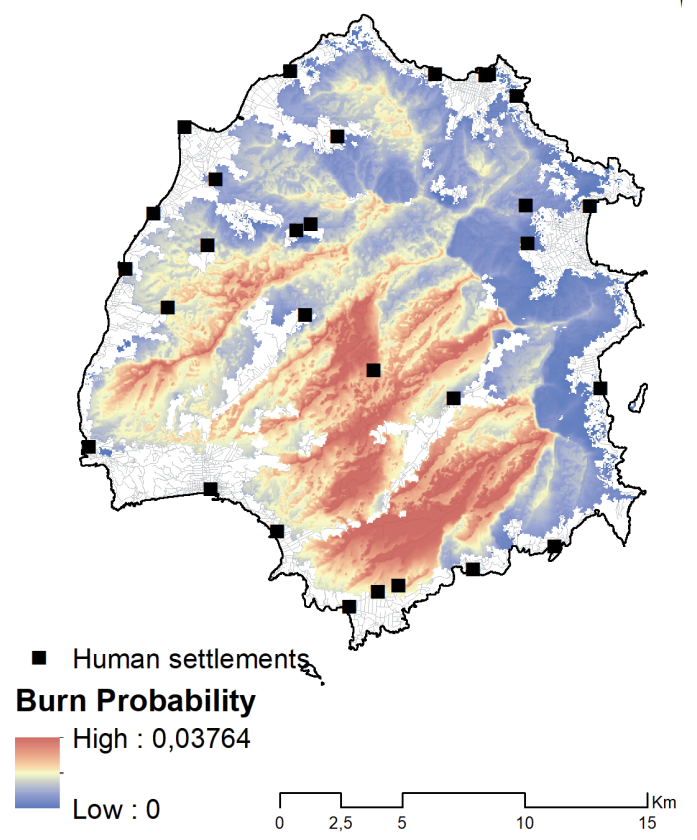

Fig. 2. a) Estimation of fire hazard in Skiathos island, Greece (Adapted from [25]), b) Estimation of burn probability in Thasos island, Greece (Adapted from [53]). 
simulations produced a fire risk map highlighting the distinct impact of key dimensions (e.g. fuels, topography etc.). Similarly, Arca et al. [31] developed fire risk and probability maps assessing Farsite performance in different weather scenarios.

Other researchers estimated the BP due to wildfires as a proxy of fire risk (Fig. 2b). Parks et al. [32] explored the effect of three factors to BP, namely, the spatial pattern of historic ignitions, the fuels structure and the geomorphology. Stockdale et al. [33] examined the impact of differentiated fire management measures (i.e. intensive fire suppression, replacement of firesensitive fuels with fire-resistant ones) to BP, indicating the decreased fire susceptibility in the treated areas. On the other hand, Scott at el. [34] exploited the fire simulation through the determination of BP and fire severity in order to quantitatively estimate the fire risk in inhabited regions. The simulation modeling outlined the fire-affected area as well as the number of fire events approaching inhabited regions.

\section{Fire Risk Assessment - Integration of Exposure and Effects Analysis}

Fire risk assessment and management may be considered a process for an integrated fire prevention through the evaluation of fire risk and the adoption of the necessary measures. There are a few studies dealing with this framework. Some prototype projects combine the fire simulation results and the estimation of fire effects to natural and cultural assets. These projects [19, 35] associate the determination of fire risk through the mapping of $\mathrm{BP}$, and the estimation of fire effects through the fire severity on any natural or cultural asset. Hence, experts' systems are used for the estimation of asset reaction to any level of fire intensity. Finally, the estimated change of any asset is calculated through the sum of BP multiplied by the reaction factor of the corresponding fire severity level. The results of an estimated positive or negative change for each asset would allow the fire managers and land use planners to establish the priority levels, strategies and appropriate preventive measures (e.g. land use restrictions etc.) for the comprehensive protection of natural and anthropogenic ecosystems $[19,36]$.

In a similar context, Massada et al. [37] explored the fire vulnerability of the Wildland Urban Interface focusing on the existing buildings located in the study area. They calculated the BP based on two scenarios. The first one incorporated the normal meteorological conditions (weather history), while the second one simulated the fire events when extreme meteorological conditions occur. In the same context, they associated the BP with the underlying land cover. Hence, they determined the fire risk of any artificial entity and land cover based on the local characteristics (types and spatial structure of fuels; climatic conditions; fire history etc.). Finally, they compared the magnitude of loss for the artificial structures and land cover for both scenarios, so that they are able to develop the respective fire strategies and tactics in any case.

Other studies limit the scope of fire effects examining the wildfire fire impacts directly on forest types features [38-39], soil [40], cultural resources [41], or the detrimental effects on human health due to released smoke [42].

\section{Fire Management}

\section{Visibility Analysis}

Visibility analysis constitutes a significant fire prevention tool that focuses on the immediate detection of any forest fire event. Pompa-García et al. [43] proposed a network of observatories for forest fire prevention taking into account the surface topography and the underlying land cover (for the establishment of the corresponding priorities). In a similar context, Sakellariou et al. [44] developed a visibility model aiming to the minimization of watchtowers locations and the maximization of visibility reducing the overlapping effect (Fig. 3). Beyond the elevation and land cover data, they used a number of certain points located at the ridges of an island. The comparative assessment of visibility potential and overlapping effect of different groups of locations revealed that beyond a certain number of given positions, the added value of visibility is negligible. Hence, the proposal of additional watchtowers would be an unrealistic scenario increasing disproportionally the financial resources.

In another project, Eugenio et al. [45], before the visibility analysis, they limited the number of candidate locations through a series of geographic operations. In detail, they initially extracted points across the ridgeline of the study area; they created the land use images through the processing of satellite images; afterwards, they combined the previously calculated points with the appropriate land use (removing points falling inside unsuitable ground); next, they calculated distinct proximity zones to road network (for accessibility purposes). After the integration of all above layers, they performed visibility analysis of the highest points and selected the group with the highest average visibility and lowest number of positions.

On the other hand, Bao et al. [46] exploited the visibility analysis and spatial optimization models in order to determine the optimal number and the most appropriate locations for the establishment of observatories. The first model involved the coverage of the entire study area (in terms of visibility) meeting the requirement of financial minimization of the suggested investment, whereas the second model required the maximization of coverage based on specific financial thresholds. To achieve this, they combined integer programming and genetic algorithms. The second model proved to be a more efficient and feasible solution.

Meanwhile, several other researchers have used a series of programming algorithms (e.g. heuristics; 


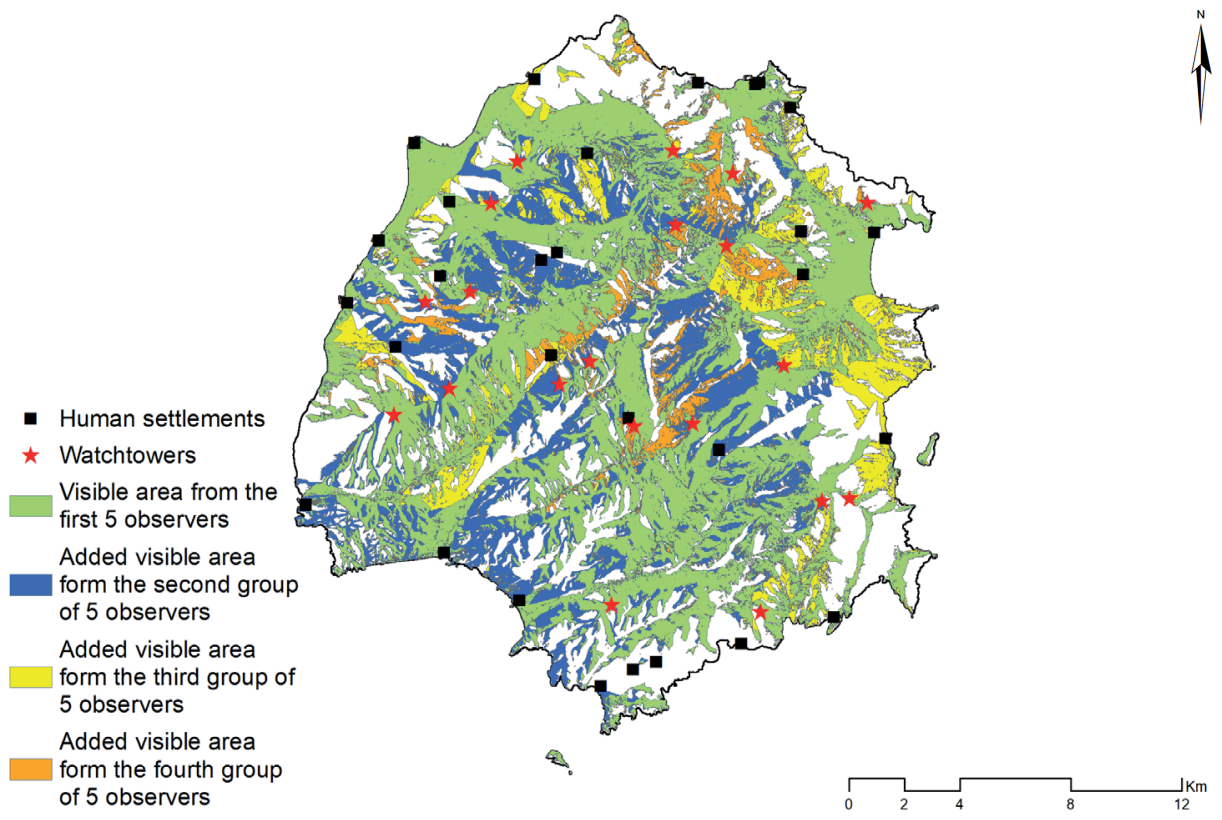

Fig. 3. Visibility analysis for immediate fire detection in Thasos island, Greece (Adapted from [44]).

sweep, genetic and spatial simulated annealing algorithm) for the optimization of visibility results and the reduction of time processing of massive data [47-49].

\section{Network Analysis and Spatial Optimization Techniques}

The cornerstone of network analysis constitutes the Dijkstra's algorithm [50] which calculates the shortest path between two given points. Hence, the network analysis has been applied to numerous practical and research problems with emphasis on the peculiarities of road (or other type) networks [7].

Kai et al. [51] developed a management system for emergency response focusing on the minimization of route between the centre and the location of the respective incident. That system was based on the integration of Dijkstra's algorithm into GIS (simulating a process of geocoding of graph theory and the implementation of Dijkstra's algorithm) which provides all the necessary spatial and attribute information. In this context, there is place for additional critical parameters (traffic, one-way restrictions) to be integrated in such systems.

Sakellariou et al. [52-54] developed Spatial Decision Support Systems for immediate initial attack of forest fires events. The concepts focus on the strategic and operational planning of fire-agency resources to minimize the possibility of expansion of detrimental fires. The establishment of differentiated spatial schemes were adjusted to find the optimal locations for the temporary parking of fire vehicles based on the population dynamicity (primarily focusing on the Wildland Urban Interface regions) (Fig. 4a) and the wildfire likelihood (Fig. 4b). Additional projects [55-58] aimed to the strategic planning of the most appropriate locations in order to meet certain criteria (financial cost minimization; conjunction of appropriate mix of forces for the minimization of escaped fires etc.) integrating simulation modeling and programming algorithms. In the same context, Kalabokidis et al. [59] designed an online forest fires management system incorporating multiple modules of coordination and human force management. Hence, they could estimate the optimal route between the fire incident and any point of interest (current location of fire vehicle; water tank etc.) presenting a certain number of alternative routes. This information system is supported by additional modules, such as the module of meteorological conditions (short term weather forecast), the fire risk and the fire behavior module. Chevalier et al. [60] developed a model for the spatial optimization of emergency response services (incidents related to medical or fire brigade services). The authors tried to find the best positions through location-allocation analysis in order to cover the majority of incidents within a predefined time of response. Hence, they computed the optimal minimum locations which cover the $90 \%$ of all incidents within 8 minutes with the integration of integer programming and GIS. The second part included the optimization of the number of human forces in the previous locations with the contribution of hypercube queuing model. This model defines the number of people required per type of incident in the nearest facility, otherwise, it proceeds to the second-best solution etc. Similarly, Murray [61] exploited spatial optimization techniques in order to increase the functional and financial efficiency of the fire services location scheme. Thus, he developed different model versions aiming to the maximization of 


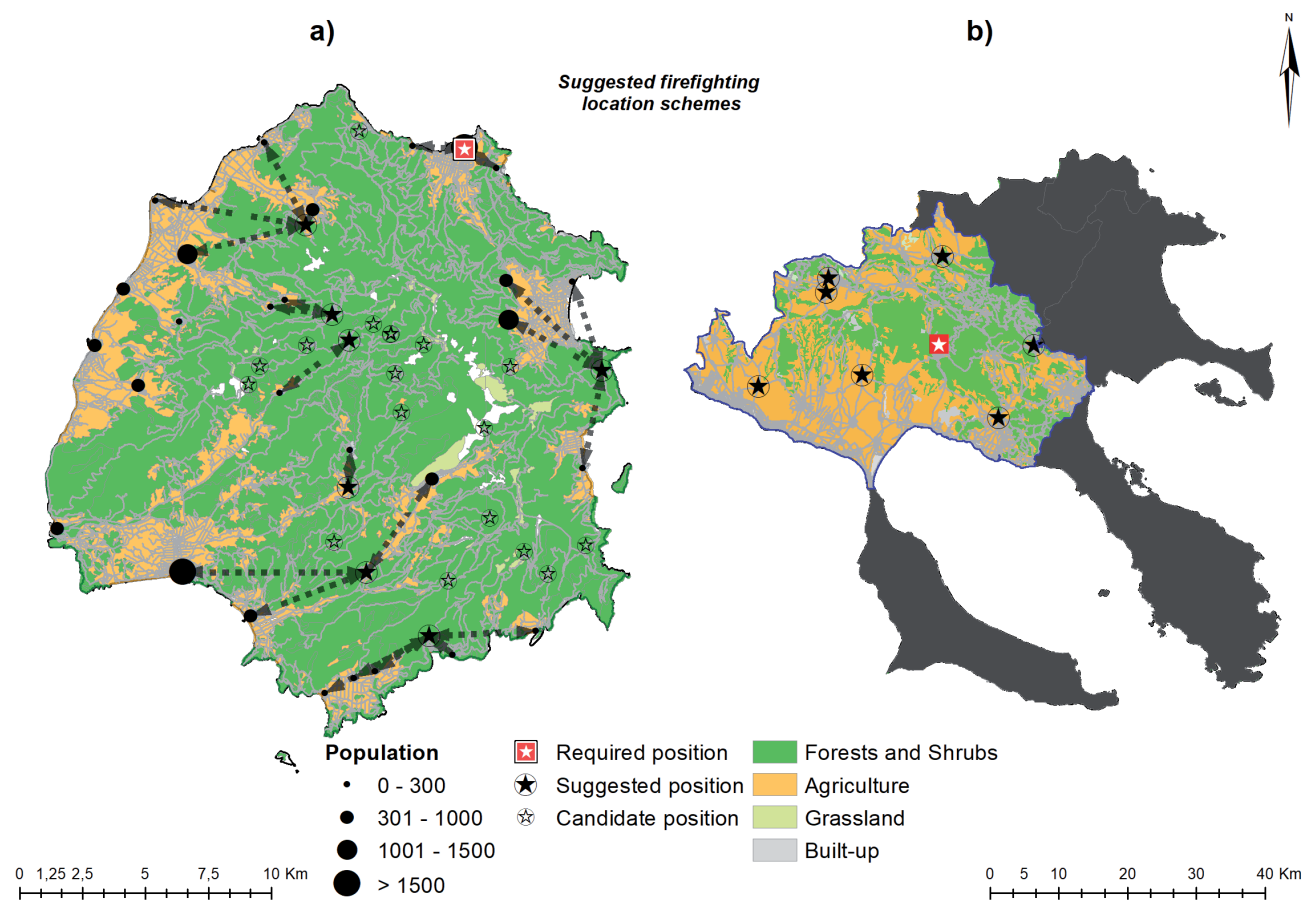

Fig. 4. a) Suggested firefighting location scheme for immediate reaction based on population size (Adapted from [52]), b) Suggested firefighting location scheme for immediate reaction based on wildfire likelihood (Adapted from [54]).

coverage and minimization of required facilities [53], so that the $90 \%$ of incidents to be approached within 5 minutes from any optimal position [61].

On the other hand, Indriasari et al. [62] studied the maximization of service area of emergency facilities within 4 minutes involving 3 optimization algorithms, namely, the genetic algorithm, tabu search and simulated annealing. The criteria for the candidate sites were based on the proximity to pre-existing facilities, primary road network and water utilities. Tabu search algorithm proved to be the most efficient, followed by the genetic and simulated annealing algorithms. It should be noted that all the algorithms yielded a $10 \%$ greater service area than the current location scheme of fire stations.

\section{Earth Observation Module - Monitoring of Land Use Changes}

The spatiotemporal monitoring of land use changes is of crucial importance, since it permits us to evaluate the pressures against forests [25]. In general, the most dominant pressures consist of urbanization (including the transformation of forest to agricultural land) and forest fires. These forces may drastically alter the forest environment and ecosystems. This type of analysis allows decision makers and planners to establish the appropriate measures to counterbalance a dominant trend against the natural environment. Hence, several methods of land use monitoring have been applied worldwide.

Before proceeding to the determination of land use changes through time, reliable land cover classification constitutes a pre-requirement. To this end, several authors have used object-based classification through the combination of high and moderate spatial resolution satellite images [63-64]. Another method for the evaluation of land cover classification is the comparative analysis of robust classifiers, such as the Artificial Neural Network (ANN), the Support Vector Machine (SVM) and the Maximum Likelihood (ML) as conducted by Srivastava et al. [65] who indicated the best performance of ANN which is then applied for change detection purposes.

In another context, Deng et al. [66] used satellite images (SPOT) of high spatial resolution in order to monitor the land use and landscape changes. After the integration of ancillary data (DEM) for the classification improvement, the authors applied the Principal Component Analysis for each pair of images for the easier discrimination of land use changes. Next, a two-phase classification took place, performing an unsupervised and a supervised classification (maximum likelihood algorithm). The validation of results was confirmed by the overall, user and producer accuracy as well as by the kappa coefficient. Finally, the authors adopted a series of spatial metrics in order to determine the types of landscape changes.

Halmy et al. [67], beyond the historic monitoring of spatiotemporal land use changes, they proceeded to the prediction of land use transformation. Hence, they initially conducted the classification of historic Landsat images exploiting the capabilities of random forest algorithm. For validation purposes, several indices were used such as confusion matrix, commission and 
omission errors, kappa statistics. Next, the matrix of change detection has been constructed and finally, they proceeded to land use forecast through Markov - Cellular Automata model, considering any certain restrictions and factors (due to the nature of land use itself, e.g. water bodies). Similarly, Hegazy and Kaloop [68] studied the evolution of land use changes focusing on urban growth and the intense consumption of rural land. The authors proceeded to a two-phase classification of historic Landsat images, namely, an unsupervised classification (a first separation) and a supervised classification based on the maximum likelihood algorithm. The normal validation (based on real land use data) and change detection (matrix of changes) techniques took place. Finally, they predicted the land use changes in the near future through the Markov-chain model.

\section{Discussion and Conclusions}

The review revealed some very interesting conclusions. As an initial preventative measure, the estimation of BP may provide valuable information for fire managers and decision makers. Some representative examples may include: the monitoring of spatiotemporal evolution of BP when a significant change(s) occurs in any crucial factor (e.g. treated fuels etc.); the estimation of high vulnerability of Wildland Urban Interface and the recommendation of the essential preventative measures, e.g. through fuel treatments [69]. However, BP modeling should be used with caution and adjustment to very real conditions. For instance, Braun et al. [70] concluded that the default settings of Burn-P3 modeling overestimated the BP compared to the actual BP based on the local conditions. Regarding fire risk maps, the advent of improved and more sophisticated artificial intelligence algorithms (e.g. artificial neural networks etc.) may significantly increase the reliability of the correct determination of fire-prone areas [71-73]. In addition, some factors that participate in fire risk estimation (social and demographic ones) should be more carefully examined, since there are no concrete arguments supporting the definite contribution to fire risk.

One other perspective constitutes the conjunction of burn/fire probability/modeling with the fuel treatments projects in order to reduce future high intensity wildfires [74-77] protecting the fragile natural and building environment from extensive damages and saving valuable resources that would be required for the full restoration of any affected region [78].

From a strategic point of view, the integration of exposure and effects analysis constitutes a valuable process. However, one of the most important steps is the detailed recording and mapping of resources. Remotely sensed data may provide a cost-effective process of data retrieval, especially in developing countries where the cost of data acquisition may be too high. Another perspective is the implementation of this type of analysis in a lower spatial scale (e.g. prefecture) integrating the fire planning to spatial planning. This process would activate the establishment of priorities for certain resources in case of fire events, allowing the more rational fire breaks planning and the determination of the most suitable evacuation routes, especially in the Wildand Urban Interface [79] where many people have lost their lives and property. Definitely, this process requires the close collaboration of all the involved agencies.

Concerning visibility analysis as a fire prevention measure, it should be noted that there are few studies dealing with the optimal establishment of watchtowers. One potential reason for this is the inherent difficulty for finding the optimal number and location of the appropriate positions, especially in regions with intense relief, since the entire process demands a significant number of iterations (i.e. calculating the visibility potential) for a limitless number of candidate points. Even though programming techniques could be adopted for the estimation of individual visibility for each potential location, there is an important level of difficulty in overlapping effect if no specific geographic hypotheses take place (avoiding unnecessary iterations for points with no meaning, e.g. rocky locations or inside a water surface etc.). The proposal of new algorithms for the reduction of candidate points is still underway [80-81].

Another promising field is related with the adoption of unmanned aerial vehicles to forest fire prevention providing the necessary information timely (e.g. immediate fire detection); saving valuable resources (e.g. due to expensive high spatial and temporal resolution remotely sensed data); increasing fire monitoring in inaccessible regions without putting the life of any person at risk. This literature gap is starting to be filled [82-87].

The network analysis module should work as an online system functioning in real time. Hence, initial attack process should be optimized saving valuable time in fire management. However, it can be easily exploited for strategic purposes determining the most appropriate locations for the fire vehicles based on fire susceptibility and/or population dynamicity [52-53]. This process may examine the effectiveness of the current location scheme of fire agencies, and if it is not optimal, to propose other solutions that maximize environmental protection and minimize the invested financial resources in the long run [61].

The Earth-Observation module for monitoring the land use changes constitutes another pillar of spatial planning. The historic evolution of land uses may permit land use planners to develop planning guidelines in order to invert forces which may degrade the natural environment in the long run. With the same tools, we may create maps of changes recording and quantifying the extent of destructive events. This last process would allow establishing updated spatial plans safeguarding 
the affected environment from any anthropogenic activity (illegal livestock, agriculture etc.) in favor of short-term economic prosperity. To this end, spatial planning must strictly delimitate the development boundaries within appropriate territory ensuring the sustainability of natural environment and the constant provision of high-quality ecosystem services [88].

\section{Acknowledgements}

This scientific publication took place within the framework of the project "Grant for Post-Doctoral Research" of the University of Thessaly, which is being implemented in the University of Thessaly and financed by the Stavros Niarchos Foundation.

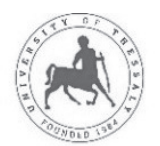

U N I VER S I T Y O F T H E S S A LY

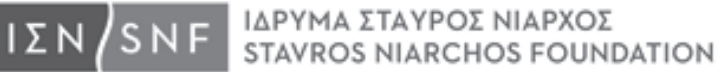

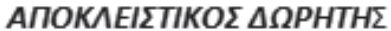

We would like to thank the anonymous reviewers for their fruitful comments that led us to the improvement of the paper.

\section{Conflict of Interest}

The authors declare no conflict of interest.

\section{References}

1. ABBATE A., LONGONI L., IVANOV V.I., PAPINI M. Wildfire impacts on slope stability triggering in mountain areas. Geosciences (Switzerland), 9 (10), 2019.

2. BADIA A., PALLARES-BARBERA M., VALLDEPERAS N., GISBERT M. Wildfires in the wildland-urban interface in Catalonia: Vulnerability analysis based on land use and land cover change. Science of the Total Environment, 673, 184, 2019.

3. CARVALHO F., PRADHAN A., ABRANTES N., CAMPOS I., KEIZER J.J., CÁSSIO F., PASCOAL C. Wildfire impacts on freshwater detrital food webs depend on runoff load, exposure time and burnt forest type. Science of the Total Environment, 692, 691, 2019.

4. CUNILLERA-MONTCUSÍ D., GASCÓN S., TORNERO I., SALA J., ÀVILA N., QUINTANA X.D., BOIX D. Direct and indirect impacts of wildfire on faunal communities of Mediterranean temporary ponds. Freshwater Biology, 64 (2), 323, 2019.

5. HAIDER W., KNOWLER D., TRENHOLM R., MOORE J., BRADSHAW P., LERTZMAN K. Climate change, increasing forest fire incidence, and the value of visibility: Evidence from British Columbia, Canada. Canadian
Journal of Forest Research, 49 (10), 1242, 2019.

6. MOREIRA F., VIEDMA O., ARIANOUTSOU M., CURT T., KOUTSIAS N., RIGOLOT E., BARBATI A., CORONA O., VAZ P., XANTHOPOULOS G., MOUILLOT F., BILGILI, E. Landscape - wildfire interactions in southern Europe: Implications for landscape management. Journal of Environmental Management, 2011.

7. SAKELLARIOU S., TAMPEKIS S., SAMARA F., SFOUGARIS A., CHRISTOPOULOU O. Review of stateof-the-art decision support systems (DSSs) for prevention and suppression of forest fires. Journal of Forestry Research, 28 (6), 1107, 2017.

8. ATUN R., KALKAN K., GÜRSOY Ö. Determining The Forest Fire Risk with Sentinel 2 Images. Turkish Journal of Geosciences (Vol. 1). Retrieved from https://dergipark. org.tr/en/pub/turkgeo $\mathbf{( 2 0 2 0}$.

9. Record wildfires push 2018 disaster costs to $\$ 91$ billion - Center for Climate and Energy Solutions. Retrieved December 7, 2020, from https://www.c2es.org/2019/02/ record-wildfires-push-2018-disaster-costs-to-91-billion/ n.d.

10. VAROL T., ERTUĞRUL M. The impact of the changing climate on fire activity in Muğla region. Polish Journal of Environmental Studies, 2015.

11. PECHONY O., SHINDELL D.T. Driving forces of global wildfires over the past millennium and the forthcoming century. Proceedings of the National Academy of Sciences of the United States of America, 107 (45), 19167, 2010.

12. RUNNING S.W. Is global warming causing more, larger wildfires? Science, 2006.

13. WESTERLING A.L., HIDALGO H.G., CAYAN D.R., SWETNAM T.W. Warming and earlier spring increase Western U.S. forest wildfire activity. Science, 313 (5789), 940, 2006.

14. Forest fires - Climate-ADAPT. Retrieved December 7, 2020, from https://climate-adapt.eea.europa.eu/knowledge/ tools/urban-adaptation/climatic-threats/forest-fires n.d.

15. JAFFE D.A., WIGDER N.L. Ozone production from wildfires: A critical review. Atmospheric Environment, 2012.

16. PAUSAS J.G., LLOVET J., RODRIGO A., VALLEJO R. Are wildfires a disaster in the Mediterranean basin? A review. International Journal of Wildland Fire, 2008.

17. Causes et consequences of forest fires $|\mathrm{OMPE}|$ Organisation Mondiale pour la Protection de l'Environnement. Retrieved December 7, 2020, from https://www.ompe.org/en/causeset-consequences-of-forest-fires/ n.d.

18. RICHARDSON L.A., CHAMP P.A., LOOMIS J.B. The hidden cost of wildfires: Economic valuation of health effects of wildfire smoke exposure in Southern California. Journal of Forest Economics, 18 (1), 14, 2012.

19. THOMPSON M.P., CALKIN D.E. Uncertainty and risk in wildland fire management: A review. Journal of Environmental Management, 2011.

20. FAIRBROTHER A., TURNLEY J.G. Predicting risks of uncharacteristic wildfires: Application of the risk assessment process. In Forest Ecology and Management 211, 28, 2005.

21. FINNEY M.A. The challenge of quantitative risk analysis for wildland fire. In Forest Ecology and Management 211, 97, 2005.

22. PARISIEN M.A. Science can map a solution to a fastburning problem. Nature, 2016.

23. EUGENIO F.C., DOS SANTOS A.R., FIEDLER N.C., RIBEIRO G.A., DA SILVA A.G., DOS SANTOS Á.B., PANETO G.G., SCHETTINO V.R. Applying GIS to 
develop a model for forest fire risk: A case study in Espírito Santo, Brazil. Journal of Environmental Management, 173, 65, 2016.

24. SIVRIKAYA F., SAĞLAM B., AKAY A.E., BOZALI N. Evaluation of forest fire risk with GIS. Polish Journal of Environmental Studies, 23 (1), 187, 2014.

25. SAKELLARIOU S., CABRAL P., CAETANO M., PLA F., PAINHO M., CHRISTOPOULOU O., SFOUGARIS A., DALEZIOS N., VASILAKOS C. Remotely sensed data fusion for spatiotemporal geostatistical analysis of forest fire hazard. Sensors (Switzerland), 20 (17), 1, 2020.

26. AMALINA P., PRASETYO L.B., RUSHAYATI S.B. Forest Fire Vulnerability Mapping in Way Kambas National Park. Procedia Environmental Sciences, 33, 239, 2016.

27. GABBAN A., SAN-MIGUEL-AYANZ J., BARBOSA P., LIBERTÀ G. Analysis of NOAA-AVHRR NDVI inter-annual variability for forest fire risk estimation. International Journal of Remote Sensing, 27 (8), 1725, 2006.

28. SHARMA L.K., KANGA S., NATHAWAT M.S., SINHA S., PANDEY P.C. Fuzzy AHP for forest fire risk modeling. Disaster Prevention and Management, 21 (2), 160, 2012.

29. VADREVU K.P., EATURU A., BADARINATH K.V. S. Fire risk evaluation using multicriteria analysis-a case study. Environmental Monitoring and Assessment, 166 (1-4), 223, 2010.

30. CARMEL Y., PAZ S., JAHASHAN F., SHOSHANY M. Assessing fire risk using Monte Carlo simulations of fire spread. Forest Ecology and Management, 257 (1), 370, 2009.

31. ARCA B. BACCIU V. Use of FARSITE simulator to produce fire probability maps in a mediterranean area. Proceedings of the $7^{\text {th }}$ Symposium on Fire and Forest Meteorology, P1.10.1. Retrieved from https://ams.confex. com/ams/7firenortheast/webprogram/Paper127440.html 2007.

32. PARKS S.A., PARISIEN M.-A., MILLER C. Spatial bottom-up controls on fire likelihood vary across western North America. Ecosphere, 3 (1), art12, 2012.

33. STOCKDALE C., BARBER Q., SAXENA A., PARISIEN M.A. Examining management scenarios to mitigate wildfire hazard to caribou conservation projects using burn probability modeling. Journal of Environmental Management, 233, 238, 2019.

34. SCOTT J.H., HELMBRECHT D.J., PARKS S.A., MILLER C. Quantifying the threat of unsuppressed wildfires reaching the adjacent Wildland-Urban interface on the Bridger-Teton National Forest, Wyoming, USA. Fire Ecology, 8 (2), 125, 2012.

35. THOMPSON M.P., SCOTT J., HELMBRECHT D., CALKIN D.E. Integrated wildfire risk assessment: Framework development and application on the lewis and clark national forest in Montana, USA. Integrated Environmental Assessment and Management, 9 (2), 329, 2013.

36. THOMPSON M.P., CALKIN D.E., GILBERTSON-DAY J.W., AGER A.A. Advancing effects analysis for integrated, large-scale wildfire risk assessment. Environmental Monitoring and Assessment, 179 (1-4), 217, 2011.

37. BAR MASSADA A., RADELOFF V.C., STEWART S.I., HAWBAKER T.J. Wildfire risk in the wildland-urban interface: A simulation study in northwestern Wisconsin. Forest Ecology and Management, 258 (9), 1990, 2009.

38. BERNIER P.Y., GAUTHIER S., JEAN P.O., MANKA F., BOULANGER Y., BEAUDOIN A., GUINDON L.
Mapping local effects of forest properties on fire risk across Canada. Forests, 7 (8), 2016.

39. PIMONT F., PARSONS R., RIGOLOT E., DE COLIGNY F., DUPUY J.L., DREYFUS P., LINN R.R. Modeling fuels and fire effects in 3D: Model description and applications. Environmental Modelling and Software, 80, 225, 2016.

40. SANTÍN C., DOERR S.H. Fire effects on soils: The human dimension. Philosophical Transactions of the Royal Society B: Biological Sciences, 2016.

41. RYAN K.C., JONES A.T., KOERNER C.L., LEE K.M. Wildland Fire in Ecosystems: effects of Fire on Cultural Resources and Archaeology. U.S. Department of Agriculture, Forest Service, Rocky Mountain Research Station General Technical Report RMRS-GTR-42, 2012.

42. ADETONA O., REINHARDT T.E., DOMITROVICH J., BROYLES G., ADETONA A.M., KLEINMAN M.T., OTTMAR R.D., NAEHER L.P. Review of the health effects of wildland fire smoke on wildland firefighters and the public. Inhalation Toxicology, 2016.

43. POMPA-GARCÍA M., ZAPATA-MOLINA M., HERNÁNDEZ-DÍAZ C., RODRÍGUEZ-TÉLLEZ E. Geospatial Model as Strategy to Prevent Forest Fires: A Case Study. Journal of Environmental Protection, 03 (09), 1034, 2012.

44. SAKELLARIOU S., SAMARA F., TAMPEKIS S., CHRISTOPOULOU O., SFOUGARIS A. Optimal number and location of watchtowers for immediate detection of forest fires in a small island. International Journal of Agricultural and Environmental Information Systems, 8 (4), 1, 2017.

45. EUGENIO F.C., ROSA DOS SANTOS A., FIEDLER N.C., RIBEIRO G.A., DA SILVA A.G., JUVANHOL R.S., SCHETTINO V.R., MARCATTI G.E., DOMINGUES G.F., DOS SANTOS G.M.D.A., PEZZOPANE J.E.M., PEDRA B.D., BANHOS A., MARTINS L.D. GIS applied to location of fires detection towers in domain area of tropical forest. Science of the Total Environment, 562, 542,2016

46. BAO S., XIAO N., LAI Z., ZHANG H., KIM C. Optimizing watchtower locations for forest fire monitoring using location models. Fire Safety Journal, 71, 100, 2015.

47. KIM Y.H., RANA S., WISE S. Exploring multiple viewshed analysis using terrain features and optimisation techniques. Computers and Geosciences, 30 (9-10), 1019, 2004.

48. MAGALHÃES S.V.G., ANDRADE M.V.A., FRANKLIN W. R. An optimization heuristic for siting observers in huge terrains stored in external memory. In 2010 10th International Conference on Hybrid Intelligent Systems, HIS 2010, 135, 2010.

49. SHI X., XUE B. Deriving a minimum set of viewpoints for maximum coverage over any given digital elevation model data. International Journal of Digital Earth, 9 (12), 1153, 2016.

50. DIJKSTRA E.W. A note on two problems in connexion with graphs. Numerische Mathematik, 1 (1), 269, 1959.

51. KAI N., YAO-TING Z., YUE-PENG M. Shortest Path Analysis Based on Dijkstra's Algorithm in Emergency Response System. TELKOMNIKA Indonesian Journal of Electrical Engineering, 12 (5), 2014.

52. SAKELLARIOU S., SAMARA F., TAMPEKIS S., SFOUGARIS A., CHRISTOPOULOU O. Development of a Spatial Decision Support System (SDSS) for the active forest-urban fires management through location planning 
of mobile fire units. Environmental Hazards, 19 (2), 131, 2020.

53. SAKELLARIOU S., PARISIEN M.A., FLANNIGAN M., WANG X., DE GROOT B., TAMPEKIS S., SAMARA F., SFOUGARIS A., CHRISTOPOULOU O. Spatial planning of fire-agency stations as a function of wildfire likelihood in Thasos, Greece. Science of the Total Environment, 729, 2020.

54. SAKELLARIOU S., SFOUGARIS A., CHRISTOPOULOU O. Location planning of fire service fleet based on forest fire susceptibility. WSEAS Transactions on Environment and Development, 16, 643, 2020.

55. GALLEGO ARRUBLA J.A., NTAIMO L., STRIPLING C. Wildfire initial response planning using probabilistically constrained stochastic integer programming. International Journal of Wildland Fire, 23 (6), 825, 2014.

56. LEE Y., FRIED J.S., ALBERS H.J., HAIGHT R.G. Deploying initial attack resources for wildfire suppression: Spatial coordination, budget constraints, and capacity constraints. Canadian Journal of Forest Research, 43 (1), $56,2013$.

57. NTAIMO L., ARRUBLA J.A.G., STRIPLING C., YOUNG J., SPENCER T. A stochastic programming standard response model for wildfire initial attack planning. Canadian Journal of Forest Research, 42 (6), 987, 2012.

58. WEI Y., BEVERS M., BELVAL E., BIRD B. A chanceconstrained programming model to allocate wildfire initial attack resources for a fire season. Forest Science, 61 (2), 278, 2015.

59. KALABOKIDIS K., ATHANASIS N., GAGLIARDI F., KARAYIANNIS F., PALAIOLOGOU P., PARASTATIDIS S., VASILAKOS C. Virtual Fire: A web-based GIS platform for forest fire control. Ecological Informatics, 16, 62, 2013.

60. CHEVALIER P., THOMAS I., GERAETS D., GOETGHEBEUR E., JANSSENS O., PEETERS D., PLASTRIA F. Locating fire stations: An integrated approach for Belgium. Socio-Economic Planning Sciences, 46 (2), 173, 2012.

61. MURRAY A.T. Optimising the spatial location of urban fire stations. Fire Safety Journal, 62 (PART A), 64, 2013.

62. INDRIASARI V., MAHMUD A.R., AHMAD N., SHARIFF A.R.M. Maximal service area problem for optimal siting of emergency facilities. International Journal of Geographical Information Science, 24 (2), 213, 2010.

63. LI W., DONG R., FU H., WANG J., YU L., GONG P. Integrating Google Earth imagery with Landsat data to improve $30-\mathrm{m}$ resolution land cover mapping. Remote Sensing of Environment, 237, 2020.

64. WȨZYK P., HAWRYŁO P., SZOSTAK M., PIERZCHALSKI M., KOK R.DE. Using Geobia and Data Fusion Approach for Land use and Land Cover Mapping. Quaestiones Geographicae, 35 (1), 93, 2016.

65. SRIVASTAVA P.K., HAN D., RICO-RAMIREZ M.A., BRAY M., ISLAM T. Selection of classification techniques for land use/land cover change investigation. Advances in Space Research, 50 (9), 1250, 2012.

66. DENG J.S., WANG K., HONG Y.,QI,J.G. Spatio-temporal dynamics and evolution of land use change and landscape pattern in response to rapid urbanization. Landscape and Urban Planning, 92 (3-4), 187, 2009.

67. HALMY M.W.A., GESSLER P.E., HICKE J.A., SALEM B.B. Land use/land cover change detection and prediction in the north-western coastal desert of Egypt using MarkovCA. Applied Geography, 63, 101, 2015.

68. HEGAZY I.R., KALOOP M.R. Monitoring urban growth and land use change detection with GIS and remote sensing techniques in Daqahlia governorate Egypt. International Journal of Sustainable Built Environment, 4 (1), 117, 2015.

69. PARISIEN M.A., WALKER G.R., LITTLE J.M., SIMPSON B.N., WANG X., PERRAKIS D.D.B. Considerations for modeling burn probability across landscapes with steep environmental gradients: An example from the Columbia Mountains, Canada. Natural Hazards, 66 (2), 439, 2013.

70. BRAUN W.J., JONES B.L., LEE J.S.W., WOOLFORD D.G., WOTTON B.M. Forest fire risk assessment: An illustrative example from Ontario, Canada. Journal of Probability and Statistics, 2010.

71. BUI Q.T. Metaheuristic algorithms in optimizing neural network: a comparative study for forest fire susceptibility mapping in Dak Nong, Vietnam. Geomatics, Natural Hazards and Risk, 10 (1), 136, 2019.

72. DE BEM P.P., DE CARVALHO O.A., MATRICARDI E.A.T., GUIMARÃES R.F., GOMES R.A.T. Predicting wildfire vulnerability using logistic regression and artificial neural networks: A case study in Brazil's Federal District. International Journal of Wildland Fire, 28 (1), 35, 2019.

73. ZHANG G., WANG M., LIU K. Forest Fire Susceptibility Modeling Using a Convolutional Neural Network for Yunnan Province of China. International Journal of Disaster Risk Science, 10 (3), 386, 2019.

74. ANA A.M., AGER A.A., DAY M.A., PALAIOLOGOU P. Improving long-term fuel treatment effectiveness in the National Forest System through quantitative prioritization. Forest Ecology and Management, 433, 514, 2019.

75. CHUNG W. Optimizing fuel treatments to reduce wildland fire risk. Current Forestry Reports, 1 (1), 44, 2015.

76. SALIS M., LACONI M., AGER A.A., ALCASENA F.J., ARCA B., LOZANO O., DE OLIVEIRA F., SPANO D. Evaluating alternative fuel treatment strategies to reduce wildfire losses in a Mediterranean area. Forest Ecology and Management, 368, 207, 2016.

77. TUBBESING C.L., FRY D.L., ROLLER G.B., COLLINS B.M., FEDOROVA V.A., STEPHENS S.L., BATTLES J.J. Strategically placed landscape fuel treatments decrease fire severity and promote recovery in the northern Sierra Nevada. Forest Ecology and Management, 436, 45, 2019.

78. LOOMIS J., SÁNCHEZ J.J., GONZÁLEZ-CABÁN A., RIDEOUT D., REICH R. Do fuel treatments reduce wildfire suppression costs and property damages? Analysis of suppression costs and property damages in US National Forests. General Technical Report, PSW-GTR-26, 70, 2019.

79. VEERASWAMY A., GALEA E.R., FILIPPIDIS L., LAWRENCE P.J., HAASANEN S., GAZZARD R.J., SMITH T.E.L. The simulation of urban-scale evacuation scenarios with application to the Swinley forest fire. Safety Science, 102, 178, 2018.

80. WANG Y., DOU W. A fast candidate viewpoints filtering algorithm for multiple viewshed site planning. International Journal of Geographical Information Science, 34 (3), 448, 2020.

81. YU T.X., XIONG L.Y., CAO M., WANG Z.H., ZHANG Y.C., TANG G. A new algorithm based on Region Partitioning for Filtering candidate viewpoints of a multiple viewshed. International Journal of Geographical Information Science, 30 (11), 2171, 2016. 
82. TIBERIU PAUL BANU, GHEORGHE FLORIAN BORLEA, CONSTANTIN BANU The Use of Drones in Forestry. Journal of Environmental Science and Engineering B, 5 (11), 2016.

83. CRUZ H., ECKERT M., MENESES J., MARTÍNEZ J.F. Efficient forest fire detection index for application in Unmanned Aerial Systems (UASs). Sensors (Switzerland), 16 (6), 2016.

84. HUA L., SHAO G. The progress of operational forest fire monitoring with infrared remote sensing. Journal of Forestry Research, 28 (2), 215, 2017.

85. LASZLO B., AGOSTON R., XU Q. Conceptual Approach of Measuring the Professional and Economic Effectiveness of Drone Applications Supporting Forest fire Management. In Procedia Engineering 211, 8, 2018.

86. PANEQUE-GÁLVEZ J., MCCALL M.K., NAPOLETANO B.M., WICH S.A., KOH L.P. Small drones for communitybased forest monitoring: An assessment of their feasibility and potential in tropical areas. Forests, 5 (6), 1481, 2014.

87. SKORPU P., MANDZUKA S., VOJVODIC H. The use of Unmanned Aerial Vehicles for forest fire monitoring. In Proceedings Elmar - International Symposium Electronics in Marine Vol. 2016-Novem, 93, 2016.

88. WANG S.W., GEBRU B.M., LAMCHIN M., KAYASTHA R.B., LEE W.K. Land use and land cover change detection and prediction in the kathmandu district of nepal using remote sensing and GIS. Sustainability (Switzerland), 12 (9), 2020

89. ABEDI GHESHLAGHI H., FEIZIZADEH B., BLASCHKE T. GIS-based forest fire risk mapping using the analytical network process and fuzzy logic. Journal of Environmental Planning and Management, 63 (3), 481, 2020.
90. AKINOLA O.V., ADEGOKE J. Assessment of forest fire vulnerability zones in Missouri, United States of America. International Journal of Sustainable Development and World Ecology, 26 (3), 251, 2019.

91. KARIMI A., ABDOLLAHI S., OSTAD-ALI-ASKARI D.K., ESLAMIAN S.P., SINGH V. Predicting Fire Hazard Areas Using Vegetation Indexes, Case Study: Forests of Golestan Province, Iran. Journal of Geography and Cartography, 2 (1), 2019.

92. BUFACCHI P., KRIEGER, G.C., MELL W., ALVARADO E., SANTOS J.C., CARVALHO J.A. Numerical simulation of surface forest fire in Brazilian Amazon. Fire Safety Journal, 79, 44, 2016.

93. WOO H., CHUNG W., GRAHAM J.M., LEE B. Forest fire risk assessment using point process modelling of fire occurrence and Monte Carlo fire simulation. International Journal of Wildland Fire, 26 (9), 789, 2017.

94. ZHENG Z., HUANG W., LI S., ZENG Y. Forest fire spread simulating model using cellular automaton with extreme learning machine. Ecological Modelling, 348, 33, 2017.

95. KUCUK O., TOPALOGLU O., ALTUNEL A.O., CETIN M. Visibility analysis of fire lookout towers in the Boyabat State Forest Enterprise in Turkey. Environmental Monitoring and Assessment, 189 (7), 2017.

96. ZHANG F., ZHAO P., THIYAGALINGAM J., KIRUBARAJAN T. Terrain-influenced incremental watchtower expansion for wildfire detection. Science of the Total Environment, 654, 164, 2019.

97. BERBEROGLU S., AKIN A. Assessing different remote sensing techniques to detect land use/cover changes in the eastern Mediterranean. International Journal of Applied Earth Observation and Geoinformation, 11 (1), 46, 2009. 